\title{
Stratification Enhancement for an Integrated Collector Storage Solar Water Heater (ICSSWH)
}

\author{
Marie SWIATEK $^{\mathrm{a}, *}$, Gilles FRAISSE ${ }^{\mathrm{a}}$, Mickael PAILHA $^{\mathrm{a}}$ \\ ${ }^{a}$ LOCIE, CNRS UMR 5271, Universit de Savoie Campus Scientifique Savoie Technolac, \\ 73376 Le Bourget du Lac Cedex, France
}

\begin{abstract}
Stratification is a key point in increasing performances of storage systems. The experimental study conducted only focuses on the charging of a high aspect ratio cavity representing the storage system of an ICSSWH, and the exchange with the solar collector is modeled by a constant heat flux. Thermal stratification is enhanced by placing in the system a stratification plate and by changing the position of the heat exchange zone between solar collector and storage. The parameters that vary in this study are the angle of inclination of the system (30, 45 and $60^{\circ}$ relative to the horizontal), the heat flux imposed (1800, 2700 and $3600 \mathrm{~W} / \mathrm{m}^{2}$ ) and the length of the stratification plate. The experiments lasted three hours. Satisfying stratification was obtained, mainly due to the reverse flow occurring in the system. However, this phenomenon increases with time and could result in creating a dead volume under the heat exchange area. This aspect will be further studied using CFD models. The impact of a good thermal stratification in the system will also be studied by determining the annual performance of the ICSSWH.
\end{abstract}

Keywords: ICSSWH, PIV, thermal stratification, reverse flow

\section{Introduction}

In France, the successive regulations for energy consumption in buildings made the resort to renewable energies mandatory, increasing the need of solar systems both thermal and photovoltaic (PV). Solar thermal systems are efficient enough because they can cover approximately $50 \%$ of the annual needs for domestic hot water (DHW). The installation cost remains the main impediment to their broad development. In addition, the relative complexity of classical systems with the collector installed on the roof and the storage inside the building can make it difficult to find available space for the storage in both new and

\footnotetext{
${ }^{*}$ Corresponding author

Email address: marie.swiatek@univ-savoie.fr (Marie SWIATEK)
} 


\begin{tabular}{|c|c|c|c|}
\hline \multicolumn{4}{|c|}{ Nomenclature } \\
\hline $\begin{array}{l}\alpha \\
\beta\end{array}$ & $\begin{array}{l}\text { thermal diffusivity }\left(\mathrm{m}^{2} / \mathrm{s}\right) \\
\text { volume expansion coefficient }\end{array}$ & $h_{\varphi}$ & $\begin{array}{l}\text { heat exhange zone height } \\
(\mathrm{m})\end{array}$ \\
\hline & $\left(\mathrm{K}^{-1}\right)$ & $L$ & system depth (m) \\
\hline$\Delta T$ & temperature difference $\left({ }^{\circ} \mathrm{C}\right)$ & $m$ & mass $(\mathrm{kg})$ \\
\hline$\lambda$ & $\begin{array}{l}\text { thermal } \\
(\mathrm{W} /(\mathrm{m} \cdot \mathrm{K}))\end{array}$ & $R a$ & Rayleigh number \\
\hline$\nu$ & kinematic viscosity $\left(\mathrm{m}^{2} / \mathrm{s}\right)$ & $R i$ & Richardson number \\
\hline$\theta$ & $\begin{array}{l}\text { inclination angle with re- } \\
\text { spect to the horizontal }\left(^{\circ}\right)\end{array}$ & $\begin{array}{l}S T \\
T\end{array}$ & $\begin{array}{l}\text { stratification coefficient } \\
\text { temperature }\left({ }^{\circ} \mathrm{C}\right)\end{array}$ \\
\hline$\varphi$ & heat flux $\left(\mathrm{W} / \mathrm{m}^{2}\right)$ & $t$ & time $(\mathrm{s})$ \\
\hline $\begin{array}{l}A_{r} \\
e_{c} \\
g\end{array}$ & $\begin{array}{l}\text { channel aspect ratio }(-) \\
\text { channel thickness }(\mathrm{m}) \\
\text { gravity }\left(\mathrm{m} / \mathrm{s}^{2}\right)\end{array}$ & $U, V, W$ & $\begin{array}{l}V \text { velocity components ac- } \\
\text { cording to the system co- } \\
\text { ordinates }(\mathrm{m} / \mathrm{s})\end{array}$ \\
\hline$H$ & system height (m) & $x, y, z$ & system coordinates \\
\hline
\end{tabular}

already existing buildings. Integrated Collector Storage Solar Water Heaters (ICSSWH) combine the advantages of low cost, minimal maintenance and ease of installation. At present, various systems are commercially available in different countries, with companies producing them mostly from the Mediterranean area or the southern hemisphere. They are usually very compact with a simple design and function almost passively. However, the main lock still impeding the increase in installation of such devices in France is their resistance to freezing conditions, as most of the time the upper part of the thermal storage is also the absorber, resulting in important heat losses to the environment, more importantly during night time. The low compacity of these systems due to their geometry is also not favorable for heat losses. Therefore, in order for ICSSWH to be as efficient as the classical solar thermal systems, heat losses should be minimized and heat transfers should be maximized to compensate the lower velocities in the system due to the absence of pumping device. Concerning heat losses, a performant insulation and a separation of the absorber from the storage part can result in a significant decrease of the thermal losses. As for heat transfer maximization, thermal stratification is a phenomenon proven to improve heat exchange in thermal storages [1]. The aim of this paper is to study the charge of the storage tank of an ICSSWH with enhanced thermal stratification.

Various types of ICSSWH exist nowadays, with different methods for heat exchange between solar radiation, storage and DHW supply. Some function with direct heat exchange; and in many configurations, the absorber is a face of 
the storage tank, and the water heated is directly used without a heat exchanger inside the storage tank. Many of those configurations use solar concentration and are called Compound Parabolic Concentration as shown in Fig. 1(a) [2]. There can also be tubular storage for which the storage tank is made up of several tubes placed inside an absorber box, as shown in Fig. 1(b) [3]. These systems are efficient in climates where there is not a high risk of reaching freezing conditions, because the opening left for solar radiation allows important heat losses. Other configurations have a storage with a triangular (Fig. 1(c)) [4] or parrallelepipedic (Fig. 1(d)) [5] storage, with only one face used as the absorber, the others being insulated. This allows to reduce heat losses during night time compared to the previoulsy presented systems. In this paper, the system studied is closer to the last configuration, except that the heat tranfer from the absorber to the tank is an indirect one, as well as that between the tank and DHW, allowing the complete insulation of the storage tank.

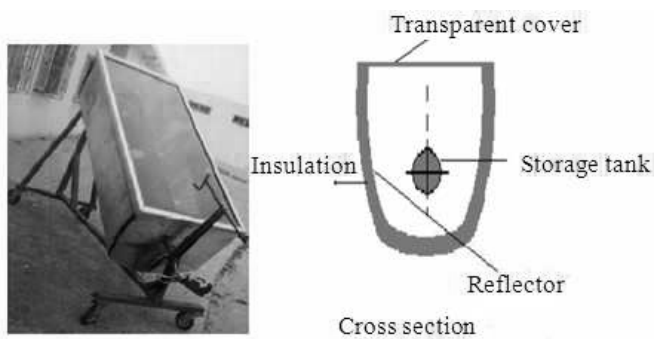

(a)

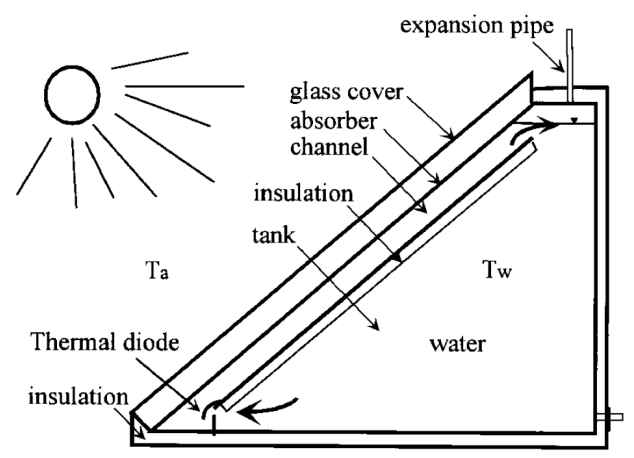

(c)

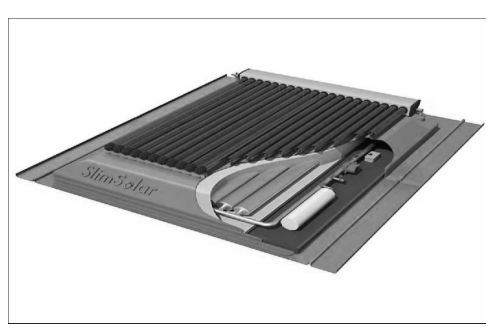

(b)

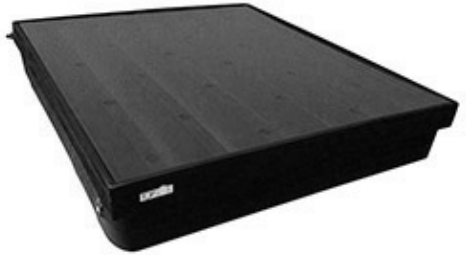

(d)

Figure 1: Various types of ICSSWH

As mentioned previously, stratification of temperatures in a thermal storage increases its efficiency due to the fact that it helps keeping lower temperatures at the bottom to maximize heat exchange with the collector, and higher temperatures at the top to have better heat exchange with DHW. In addition, a more efficient storage means that the whole ICSSWH will be more efficient. 
This phenomenon has been characterized and quantified by various parameters and many authors in order to compare systems. Therefore, different definitions can be found in literature to describe thermal stratification and evaluate its efficiency, some based on graphical observations, others on figures of merit or non-dimensional numbers, but also some based on first or second law of thermodynamics calculations [6]. In many papers, the definitions used for the dynamic (charge and discharge) and static (storage) parts of the cycle are separated. In our case, as only the charge is considered, the definitions used for dynamic mode were reviewed. Among all these, the most relevant definitions adaptable to our case are the following :

- The temperature difference $\Delta T$ between the highest and lowest temperatures measured inside the system at a given time $t$. This parameter has the advantage to be very easy to know once the temperature profiles are available, and it gives a good insight of the degree of stratification inside the system. However, it gives no information about the level of temperature present.

- The Richardson number $R i$, which is believed to be the most relevant non dimensional parameter to describe the ability of a system to establish proper thermal stratification [7]. Its expression is given by Eq. (1):

$$
R i=\frac{g \cdot \beta \cdot \cos (\theta) \cdot \Delta T \cdot L_{c}}{V_{c}^{2}}
$$

where $\beta$ is the volume expansion coefficient $\left(\mathrm{K}^{-1}\right), \theta\left(^{\circ}\right)$ is the angle of inclination with respect to the horizontal, and $L_{c}(\mathrm{~m})$ and $V_{c}(\mathrm{~m} / \mathrm{s})$ are respectively the characteristic length and velocity.

- The stratification coefficient $S T$ defined by Eq. (2) [8]:

$$
S T=\frac{1}{m_{r e s}} \sum_{i} m_{i}\left(T_{i}-\bar{T}\right)^{2}
$$

with $m_{\text {res }}(\mathrm{kg})$ the mass of water in the storage tank, $T_{i}(\mathrm{~K})$ and $m_{i}(\mathrm{~kg})$ respectively the average temperature and the mass of water contained in the node $i$, and $\bar{T}(\mathrm{~K})$ the average temperature in the storage tank at time $t$.

The previously introduced parameters will be used to characterize and compare the experimental configurations tested for this study and decide which ones are the more efficient.

Ways to improve thermal stratification and hence increase ICSSWH efficiency have been studied in literature. Several authors resorted to an insulated plate placed parallel to the flat collector and close to it $[9,10]$. This results in a channel in which the water is heated, then going up directly at the top of the storage. This system allows the separation of upward and downward flow, thus 
reducing mixing which is one of the main causes of stratification destruction. By adding a thermal diode at the bottom or the top of the channel $[4,11]$, this system also helps reducing losses during the night impeding the flow in the channel to go downward and cooling the whole storage. The drawback of this solution reveals when the storage is already charged : if the temperature at the top part of the storage near the channel outlet is hotter than the fluid being heated in the channel, it can result in the blocking of the upward flow. A mean to overcome this problem was suggested by Smyth et. al [12, 13, 14], which consisted in a perforated plate in order for the fluid to be deposited at its corresponding layer of temperature from the channel to the storage part of the ICS.

In order to reduce losses to the environment, the aspect ratio of the system also plays its part as it has an influence on the thermocline, which is the size of the area separating the hot and cold fluid zones. The thermocline thickness is another parameter used in literature to characterize thermal stratification in energy storages as the thinner it is, the more the storage is considered close to a perfectly stratified system. It was not decided to be a studied parameter in this study because the values found were not in agreement with the graphical observations for stratification: some cases with smaller temperature difference and a lower average temperature stored could have a better value for the thermocline thickness. According to Souza [15], the increase in aspect ratio of two storages with the same thermocline thickness reduces the volume of fluid in this area, and Lavan and Thompson [1] underlined that the higher aspect ratios implied more losses to the environment. Therefore, an aspect ratio of 3 or 4 would be a good compromise between thermal performances and cost of insulation and materials. In addition, Hahne and Chen [16] and Nelson et al. [17] showed that the improvement of stratification was negligible for aspect ratios superior to respectively 4 and 3 .

In this paper, we are going to focus on one particular ICSSWH system with a solar loop to collect solar radiation which indirectly exchange heat with the storage tank over a height of $0.2 \mathrm{~m}$. The charging of the storage system has already been experimented previously by Souza [15], which configuration consisted in a parallelepiped storage tank of high aspect ratio $(H / L=13)$ heated at the bottom with a constant heat flux, as shown in Fig. 2. The value of the aspect ratio is high compared to the recommended values of literature due to the fact that for this system architectural integration was also taken into account. Three values of angle $\theta\left(30,45\right.$ and $\left.60^{\circ}\right)$ and of heat flux $\varphi(1800$, 3600 and $5400 \mathrm{~W} / \mathrm{m}^{2}$ ) were studied during three hours.

In such system, the flow was shown to be two-dimensional in the lower part and three-dimensional in the top part, the evolution of the boundary between $2 \mathrm{D}$ and $3 \mathrm{D}$ flows changing according to the instant in time of the experiment and the value of the Rayleigh number defined by Eq (3): 


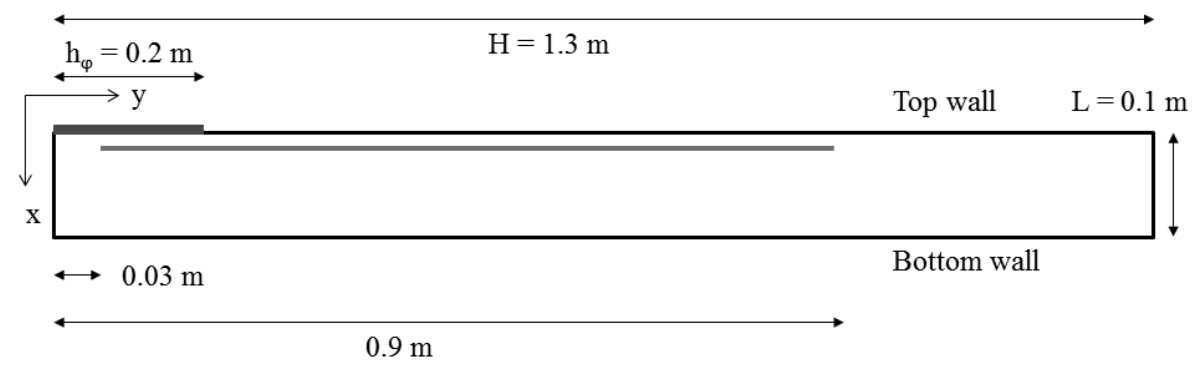

Figure 2: Schematic representation of the previously studied case with stratification plate $[15,18]$, the one represented being denoted Hbf

$$
R a_{\varphi, h_{\varphi}}=\frac{g \cdot \beta \cdot \cos (\theta) \cdot h_{\varphi}^{4} \cdot \varphi}{\alpha \cdot \nu \cdot \lambda}
$$

Also, very poor thermal stratification was observed, with a maximal temperature difference between the top and the bottom of the storage tank of only $4.2{ }^{\circ} \mathrm{C}$ after charging for three hours at an angle of $30^{\circ}$ and a heat flux of 5400 $\mathrm{W} / \mathrm{m}^{2}$. In order to improve stratification, a device was inserted into the storage tank consisting of an acrylic plate placed parallel to the top wall creating a channel. It allows to separate the upward and downward flows and to reduce the mixing effect. It was also proven that it made the flow two dimensional, thus allowing the use of 2D numerical model to further study several parameters for the plate. In the experimental study conducted by J. Souza, the plate was placed $8 \mathrm{~mm}$ away from the top wall (see Fig. 2), and only the case with the angle of $45^{\circ}$ and the heat flux of $3600 \mathrm{~W} / \mathrm{m}^{2}$. It showed that this configuration did not significantly improved thermal stratification in the system. In addition, the plate at this distance does not generate enough pressure drop to reduce the velocity of the fluid flow. Henceforth, a numerical study of the plate was conducted [18], and it showed that stratification would be enhanced significantly if the channel thickness was smaller. However, if the plate is too close to the top wall, it gets warmer due to the hot upward flow circulating in the channel, thus creating a secondary boundary layer on the cavity-side of the stratification plate, annihilating its effect. The optimal solution would be to have an adiabatic plate, or to insulate it, which was applied in the prototype of this system [19]. The annual performance of this prototype was satisfactory, as it was only a bit lower than that of a more classical system such as the thermosyphon: for the Chambery climate, with an angle of $30^{\circ}$, a collector surface of $2 \mathrm{~m}^{2}$, a storage volume of $150 \mathrm{~L}$ and a $\mathrm{DHW}$ need of $200 \mathrm{~L} /$ day at $45^{\circ} \mathrm{C}$, the solar fraction was of $37.8 \%$ [20]. However in this system a satisfactory thermal stratification was never reached. 


\section{New configuration}

In order to improve this parameter and thus get a better efficiency for the whole system, the idea was at first to find means to increase pressure drop to reduce velocities. Solutions found in literature such as perforated plates or obstacles were proven useless due to the already small order of magnitude of the velocities occurring in the system. Therefore, this kind of solutions were abandoned, and another solution to improve stratification is to change the location of the heat input that influences the buoyancy forces in the system [21]: the higher the heat exchange zone in the system, the lower the buoyancy force due to the fact that there is less height to be heated (in the formula $\Delta \rho . g . H$ ). The decrease in this force tends to reduce velocities in the system, hence minimizing the mixing effects that are partly responsible for stratification destruction.

As a consequence, we placed the heat exchange zone in the middle part of the top wall of the cavity. However, in this case, the stratification plate is mandatory in order for the volume under the heat exchange zone not to be a dead volume useless in terms of energy storage. In this case, the plate also ensures that the fluid loops in the storage tank, such that the cold fluid at the bottom is piped to the heat exchange zone, heated up and placed at the top. This way, the heat exchange between the solar loop and the tank will be more efficient than if the plate was not present, and thermal stratification achieved would generate hotter temperatures on the top part of the system. This allows a better heat exchange with the domestic hot water (DWH) heat exchanger placed inside the tank (not represented here).

Two plate lengths are studied in this paper : one stopping at the end of the heat exchange zone $(y=0.75 \mathrm{~m})$ - denoted Hme ( $\mathrm{m}$ standing for the fact that the heat exchange is placed in the middle of the top wall; and e for end), and another stopping at a fixed length $0.9 \mathrm{~m}$ away from the bottom of the system denoted Hmf (f standing for fixed).

This new configuration brings about a set of new physical phenomena that were not encountered in the previous case. Actually, the fact that the heat exchange zone is placed near the end of the channel generates a reverse flow. To characterize this phenomenon, a modified Rayleigh number $R a_{\varphi, h_{\varphi}}^{*}$ is used taking into account the channel aspect ratio $A_{r}=e_{c} / h_{\varphi}: R a_{\varphi, h_{\varphi}}^{*}=R a_{\varphi, h_{\varphi}} \cdot A_{r}$.

The reverse flow has obviously an effect on the thermal stratification in the storage tank, and this study will help understanding it. Reverse flow has been studied both experimentally and numerically with both air and water as working fluids, but its origin is still not surely known [22]. The first experimental studies of this phenomenon were conducted by Sparrow et al. [23] with water as working fluid. They concluded that the Nusselt number was not affected by the appearance of the reverse flow. Li et al. [24] numerically studied reverse flow of air neglecting radiative transfer and without using the Boussinesq approximation but giving laws of variations of quantities according to the temperature. The results showed that the maximum velocity was nearly independent from the spacing between the heated and adiabatic wall and that for a fixed value of the modified Rayleigh number $R a_{\varphi, h_{\varphi}}^{*}$, the reverse flow increases with the 
spacing between the walls. Brangeon [25] numerically researched the influence of the angle of inclination and saw that the more the system was tilted close to the horizontal, the more the heat exchanges, the flow rate and the reverse flow area diminished. Dupont et al. [22] experimentally studied the reverse flow of air and concluded that the boundary layer thickness did not seem affected by the change in heat flux imposed. For an equivalent configuration, Samot et al. [26] defined areas of occurrence for this phenomenon according to the Rayleigh number $R a_{\varphi, h_{\varphi}}$ and the aspect ratio of the channel. For ventilation purposes, Khanal et al. [27] inclined the adiabatic wall such that the outlet is as thick as the boundary layer to prevent reverse flow from happening as this phenomenon tends to decrease the total mass flow in the system.

All these studies allow to keep in mind the main parameters influencing the reverse flow. However, they all are placed in an open environment, which is not the case in this study. In addition, our channel geometry is different as there is a large part of unheated walls under the heated zone, and in some cases above as well. All these changes have an influence on the reverse flow that cannot be quantified as it has never been studied before to the knowledge of the authors.

In our experimental set up, the reverse flow cannot be studied very deeply due to the fact that there is no visibility inside the channel for PIV measurements. Therefore no precise data will be observed in this area, but the velocity profiles near the channel outlet are available.

\section{Experimental setup}

\subsection{Bench description}

The system studied experimentally consists in a $1.3 \mathrm{~m}$ high, $0.62 \mathrm{~m}$ wide and $0.1 \mathrm{~m}$ deep cavity made up of glass, as shown in Fig. 3. It is filled with distilled water seeded with polyamid seeding particles (PSP) of density 1.03 and average diameter $5 \mu \mathrm{m}$. The main cavity is divided into three cavities by means of two acrylic "splitting" plates. The resulting central cavity is $0.3 \mathrm{~m}$ wide and is the one in which the particle image velocimetry (PIV) measurements will take place. Both side cavities are $0.15 \mathrm{~m}$ wide. One of them is used to install all the measuring devices, while the other is left untouched in order to leave a window open to PIV measurements. The two acrylic splitting plates come up with a groove to slide in the $4 \mathrm{~mm}$ thick acrylic stratification plate $5 \mathrm{~mm}$ apart from the front wall. The purpose of the splitting plates is to be considered as adiabatic walls. The whole system - apart from the side walls - is insulated with $6 \mathrm{~mm}$ thick extruded polystyrene of thermal conductivity $\lambda=0.035 \mathrm{~W} /(\mathrm{m} . \mathrm{K})$, thus creating a third type boundary condition of fixed heat exchange coefficient with ambient temperature. A gap is left in the middle of the insulation to allow the laser sheet for PIV to illuminate the middle plane of the system.

The constant heat flux imposed is controlled by means of a heating system located in the middle of the front wall. This system consists in three electrical heaters $(0.2 \times 0.2 \mathrm{~m})$, sandwiched between on the one hand a stainless steel plate in contact with the water in the system also insuring that the heating system 


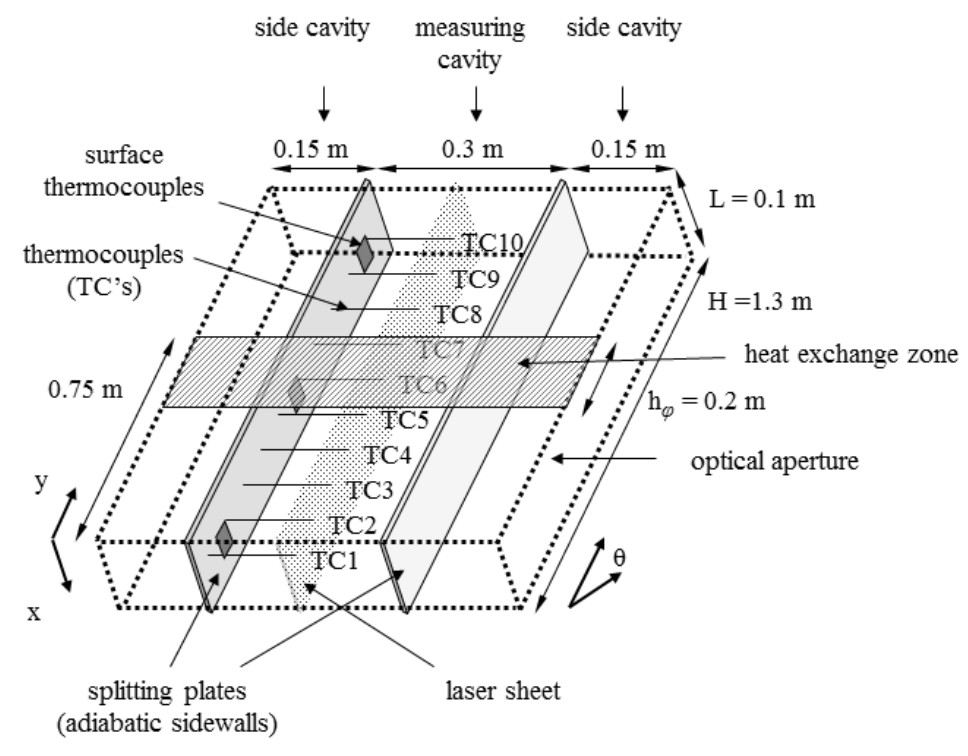

Figure 3: Diagram of the cavity with the thermocouples

is water proof, and on the other hand three layers of $5 \mathrm{~mm}$ thick insulating silicon foam. On the back of the heaters, in the middle of the central heater are found two heat flux sensors $(0.1 \times 0.1 \mathrm{~m})$ to measure the heat flux that is not going towards the water. There is also a thermocouple on each heater to monitor its temperature. On each side of the layer of silicon foam adjacent to the heaters are found eight couples of K-type thermocouples in order to give another estimation of the heat flux not going to the water, as the heat flux sensors have not been calibrated but have the uncertainty given by the supplier, which is of $30 \mu \mathrm{V} /\left(\mathrm{W} / \mathrm{m}^{2}\right)$.

Eighteen T-type thermocouples are also installed in the system. Ten of them are placed in the splitting plate to get the temperature at the center plane of the middle cavity. The position of the first thermocouple at the bottom is $x$ $=5 \mathrm{~cm}, y=11 \mathrm{~cm}$, incremented along the $y$-axis by $12 \mathrm{~cm}$, resulting in the tenth thermocouple being placed at $x=5 \mathrm{~cm}, y=119 \mathrm{~cm}$. Six thermocouples are found three at each side of the same splitting plate in order to verify the assumption of adiabatic wall. The first pair is placed at the bottom is located with the coordinates $x=5 \mathrm{~cm}, y=18 \mathrm{~cm}$, with a distance between the next pairs of $48 \mathrm{~cm}$ along the $y$-axis.

Another thermocouple is used to monitor the ambient temperature during the experiment.

All thermocouples have been calibrated and have an uncertainty of $\pm 0.2{ }^{\circ} \mathrm{C}$. 


\subsection{Protocol}

The water temperature can be controlled at the initial time by means of a thermobath and a heat exchanger placed next to the system. The temperature is thus initialized before the system is filled, giving a uniform temperature of $20^{\circ} \mathrm{C} \pm 0.5^{\circ} \mathrm{C}$. The temperature inside the room of experiment could not be controlled, so it usually varied around $23{ }^{\circ} \mathrm{C} \pm 1{ }^{\circ} \mathrm{C}$. In our case, most of the experiments last 3 hours in order to limit the effects of a varying ambient temperature, and also to be able to start and stop an experiment in the length of a working day. In fact, after each experiment, the water is transferred to a reservoir in order for the temperature to be initialized for the next experiment. Concerning PIV measurements, the central plane is divided into eleven planes of study for the camera to be able to capture the entire system. The system is monitored every five minutes, and it takes about $30 \mathrm{~s}$ for the acquisition to be completed.

For the cases studied, the varying parameters were the length of the stratification plate, the values of the constant heat flux imposed and the angle of inclination of the system. Concerning the latter, the same values as in the previous study have been chosen : 30,45 and $60^{\circ}$ relative to the horizontal axis. Regarding the heat flux, the values chosen are $1800 \mathrm{~W} / \mathrm{m}^{2}, 2700 \mathrm{~W} / \mathrm{m}^{2}$ and $3600 \mathrm{~W} / \mathrm{m}^{2}$.

\begin{tabular}{c|ccc}
\hline \hline$R a_{\varphi, h_{\varphi}}$ & \multicolumn{3}{|c}{ Tilt angle to the horizontal $\left(^{\circ}\right)$} \\
Heat flux $\left(\mathrm{W} / \mathrm{m}^{2}\right)$ & 30 & 45 & 60 \\
\hline 1800 & $\mathrm{~A} 30 \mathrm{P} 18$ & $\mathrm{~A} 45 \mathrm{P} 18$ & $\mathrm{~A} 60 \mathrm{P} 18$ \\
& $7.97 \times 10^{10}$ & $6.51 \times 10^{10}$ & $4.60 \times 10^{10}$ \\
\hline 2700 & $\mathrm{~A} 30 \mathrm{P} 27$ & $\mathrm{~A} 45 \mathrm{P} 27$ & $\mathrm{~A} 60 \mathrm{P} 27$ \\
& $1.20 \times 10^{11}$ & $9.77 \times 10^{10}$ & $6.91 \times 10^{10}$ \\
\hline 3600 & $\mathrm{~A} 30 \mathrm{P} 36$ & $\mathrm{~A} 45 \mathrm{P} 36$ & $\mathrm{~A} 60 \mathrm{P} 36$ \\
& $1.59 \times 10^{11}$ & $1.30 \times 10^{11}$ & $9.21 \times 10^{10}$ \\
\hline \hline
\end{tabular}

Table 1: Cases studied experimentally and the value of the Rayleigh number

Concerning the values of the modified Rayleigh number, they vary between 1$4 \times 10^{9}$, the highest value being obtained for A30P36 and the lowest for A60P18. The values decrease with the heat flux imposed and with increasing values of the tilt angle, just as the results shown in the table for $R a_{\varphi, h_{\varphi}}$. For both Rayleigh numbers, the values are characteristic of the end of the laminar flow and the beginning of the transitional flow [28]. In both cases, the configuration Hme or Hmf is not specified as the parameters taken into account for the Rayleigh determination do not involve the length of the plate but only the channel thickness and the heat exchange length, which is the same for both cases.

\section{Thermal behavior}

For all cases, we performed a global energy balance of the system. The injected flux $\varphi_{i n j}$ in the water can be measured thanks to the power supplied 
by the generator and the thermocouples and heat flux sensors placed on the other side of the heating elements. The heat flux lost $\varphi_{h l}$ can be estimated knowing the thermal conductivity of the glass and of the insulating panels and their respective thickness. An average discrepancy rate was calculated as $\left(\left(\varphi_{i n j^{-}}\right.\right.$ $\left.\varphi_{h l}\right) / \varphi_{i n j}$ ), and values around $10 \%$ were obtained for all cases.

The adiabadicity of the "splitting" plates was also verified by determining $\varphi_{\text {lat }}$. The maximum value of $0.6 \mathrm{~W}$ was obtained for the HmfA60P36 case at $t=3 \mathrm{~h}$, which corresponds to less than $0.5 \%$ of the injected flux; and for all cases the values varied around $0.2-0.3 \%$ of the injected flux, which validate the hypothesis of adiabatic wall.

Concerning the losses in the other walls (top-bottom and superior-inferior, ie the walls of the measuring cavity echanging with the environment), their value depend on the position inside the cavity. Actually, as the room temperature was sometimes higher than the bottom temperature inside the system, a heat gain can be observed in this part whereas at the top of the system, the temperature is always higher than the room temperature after one hour of charge or more, so there are heat losses in this part. The mean value of losses inside the system (balance between gains at the bottom and losses at the top) increases with time and its value represents less than $1 \%$ of the injected flux after three hours of charge.

Fig. 4 shows the evolution of temperature over time in the cavity for different thermocouples. The trend is linear except for the beginning, and it is possible to notice that depending on the position in the cavity, the time of establishment of linear variation is different: it is less than $10 \mathrm{~min}$ for the thermocouple located at the top while for the thermocouple located in the middle it is nearer to 30 min. It is also possible to notice that, depending on the configuration studied, the slope is not the same at a given heat flux: cases with the plate ending at the end of the heat exchange zone (Hme) stratify better than those having a longer stratification plate (Hmf). The linear evolution of temperature is expected for cases with constant heat flux imposed and a well insulated system.

In order to qualify stratification, graphical methods representing the temperature pofiles along the system can be used as shown in Fig. 5. These results show that the systems with lower angle have a better thermal stratification as they achieve higher temperatures at the top nodes of the storage tank, keeping a lower temperature at the bottom. Besides, as noticed previously, cases with longer stratification plate reach lower temperatures at the top than cases with stratification plate stopping at the end of the heating zone. Fig. 5 also shows a significant increase in stratification compared to the previously studied case [15]. Actually, the case Hbf shown is heated from the bottom until the line $y$ $=0.2 \mathrm{~m}$, and the stratification plate goes until the line $y=0.9 \mathrm{~m}$ as shown in Fig. 2.

Based on these profiles, it is possible to determine the temperature difference in the tank at a given time. After a three hour charge, higher results of 22.9 ${ }^{\circ} \mathrm{C}$ were obtained for case HmeA30P36, and then values decreased with power supply and increasing inclination angles to reach $10^{\circ} \mathrm{C}$ for the case HmfA60P18. The determination of the stratification coefficient ST shows consistent results 


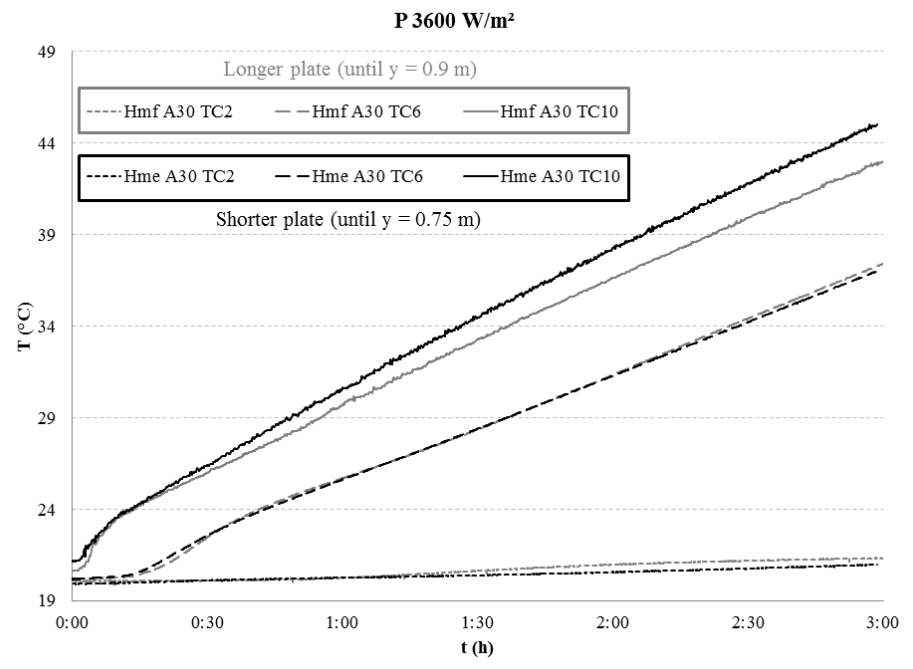

Figure 4: Temperature evolution over time in the cavity at various positions for cases inclined with $30^{\circ}$ and heated with a constant heat flux of $3600 \mathrm{~W} / \mathrm{m}^{2}$

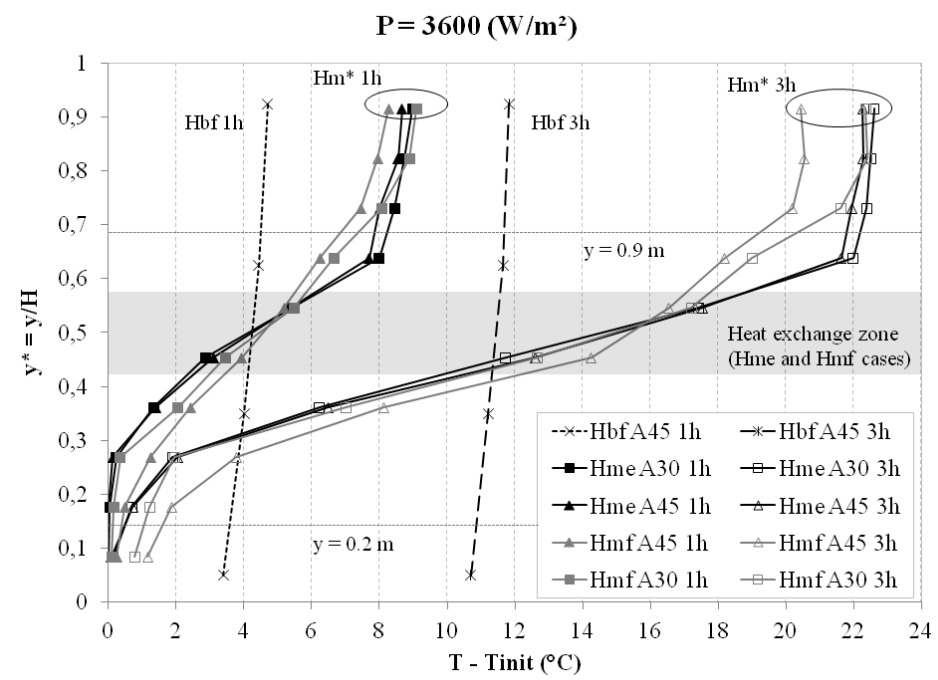

Figure 5: Temperature profiles after $1 \mathrm{~h}$ and $3 \mathrm{~h}$ of charging the system with a constant heat flux of $3600 \mathrm{~W} / \mathrm{m}^{2}$, compared with the previous case with stratification plate [15] (Hbf)

(Fig. 6). It is possible to notice that this trend evolution is the same for the Rayleigh number previously determined in Table 1. It means that for our cases, 
the higher the Rayleigh number, the better the stratification.

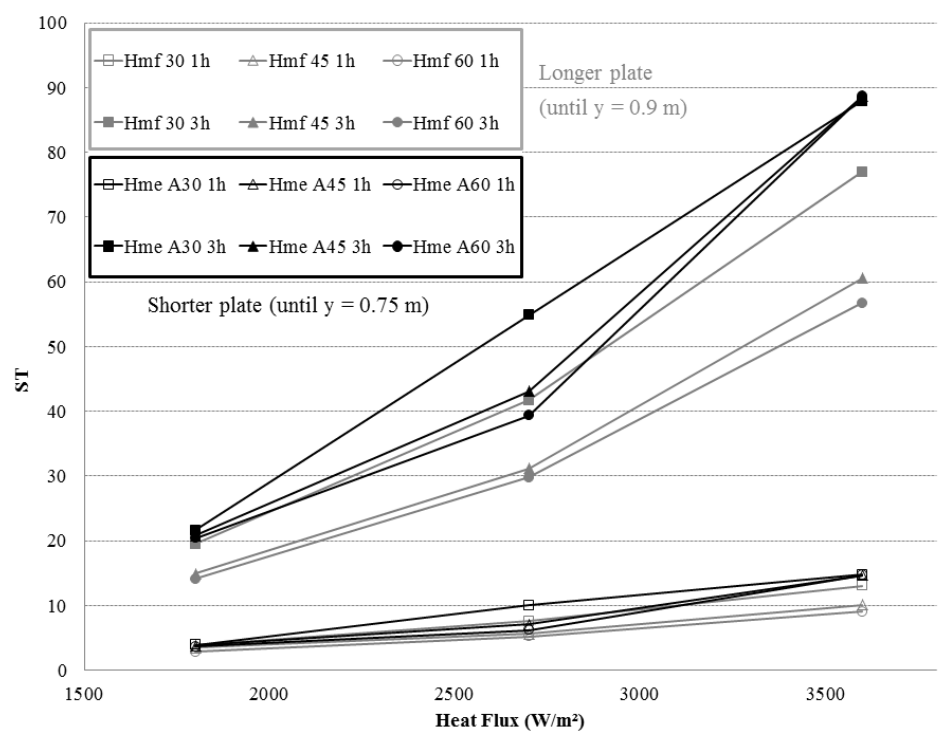

Figure 6: Values of the stratification coefficient ST according to different cases, angles and heat flux supplied

Values of the Richardson number for the Hme and Hmf cases were all superior to 1 , which means that a good thermal stratification is likely to take place in the tank.

\section{Flow characterization}

In order to characterize the flow in the system, several parameters are taken into account. Once the PIV acquisition is done, a velocity field can be found, allowing to compute other quantities.

The vorticity $\omega_{z}$ of a $2 \mathrm{D}$ flow, determined by Eq. (4), describes the local rotation of the fluid around the $z$-axis.

$$
\omega_{z}=\frac{\partial V}{\partial x}-\frac{\partial U}{\partial y}
$$

Vorticity in a fluid highlights the areas where the fluid is spinning relative the the point being looked at. It can be the case when vortices are present inside a flow, or near the walls due to high shear stresses. Both phenomena are present in the system in our case.

The divergence of a velocity field in a steady state 2D flow is given by Eq. (5): 


$$
\frac{\partial U}{\partial x}+\frac{\partial V}{\partial y}=0
$$

If this equation is not verified, then it means that the term linked to the third velocity component $\partial W / \partial z$ is not equal to zero. In this case, the flow cannot be considered $2 \mathrm{D}$ as the mass flow is not conserved in the study plane. Therefore this quantity allows to verify the $2 \mathrm{D}$ aspect of the flow. Mass conservation is also checked by comparing the up and down flow rates at given lines in the study plane: one at $y=0.75 \mathrm{~m}$ (the channel outlet for Hme cases), and from $y$ $=0.9 \mathrm{~m}$ (the channel outlet for Hmf cases) to $y=1.2 \mathrm{~m}$, one every $10 \mathrm{~cm}$, as shown in Fig 7. Unless otherwise specified, the values of velocities given in the following paragraph are the $y$-axis component, meaning the velocity $\mathrm{V}$.

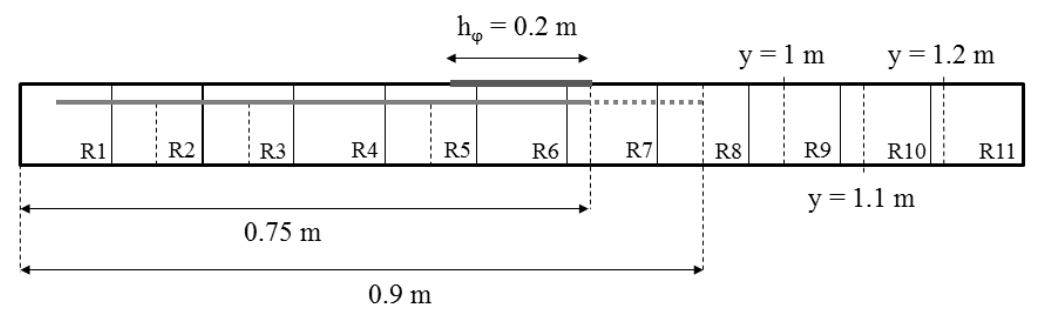

Figure 7: Representation of the system with the PIV measurement regions and the lines used for post processing

For all cases, the mass balance has been evaluated for all the previously mentioned profiles (at the channel outlet and above the stratification plate). The average values were around $0.021 \mathrm{~kg} /(\mathrm{m} . \mathrm{s})$ and $0.032 \mathrm{~kg} /(\mathrm{m} . \mathrm{s})$ after one and three hours respectively for both cases. These values are of the same order of magnitude as the maximal ones obtained by J. Souza [15] when studying the stratification plate case, which was concluded to be predominantly bidimensional (2D). Combined with the observations of divergence field in the study plane, the same conclusion can be reached in our case: only restricted areas show a three-dimensional characteristic. This conclusion is important as it allows the use of $2 \mathrm{D}$ computations to model this system using computational fluid dynamics (CFD).

The profiles of vorticity and divergence in the entire system for the worst case of mass balance is shown in Fig. 8 .

Concerning the fluid flow behavior, it is possible to notice several kinds of phenomena occurring in the system, as represented in Fig. 9(a).

Zone A represents the plume going out of the channel toward the upper part of the system. This ascending motion is created by the density difference found locally in the system: the fluid is heated in the channel in the neighborhood of the heat exchange zone, activating buoyancy forces and creating the flow for the system to be at equilibrium. Plume entrainment can be observed in the surrounding fluid. In this area, the maximum velocities measured for all cases 

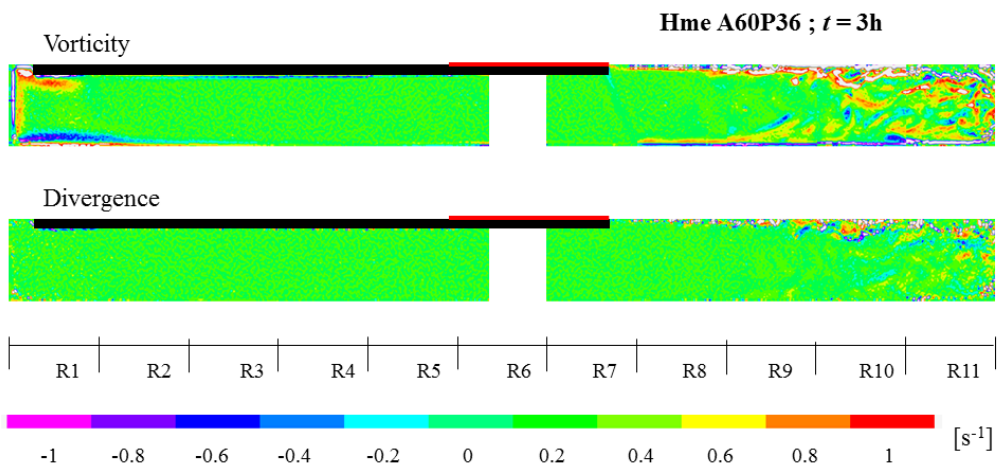

Figure 8: Vorticity and divergence of the case with shorter plate (Hme) inclined at $60^{\circ}$ and heated with a constant heat flux of $3600 \mathrm{~W} / \mathrm{m}^{2}$, at $t=3 \mathrm{~h}$

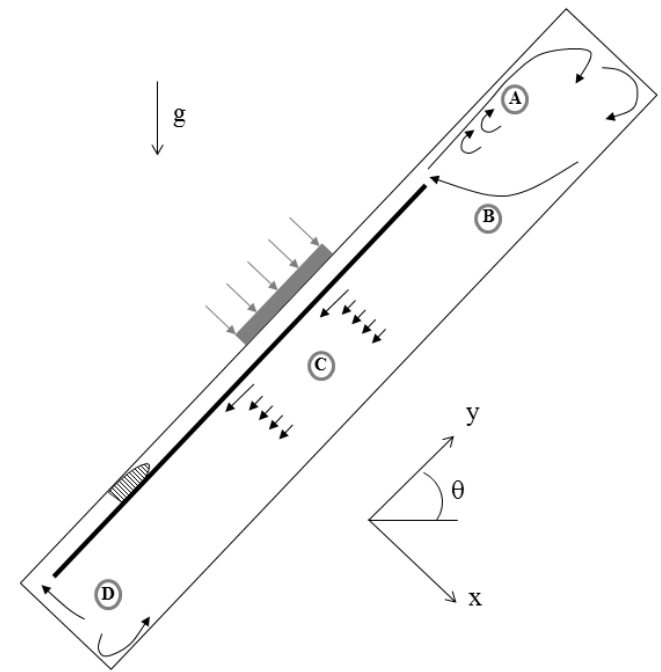

(a)

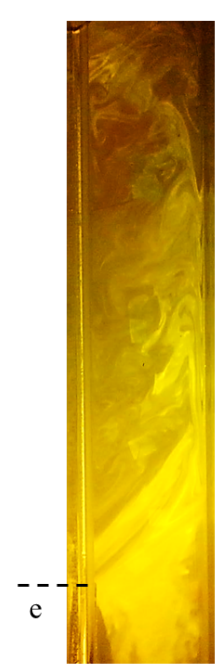

(b)

Figure 9: (a) Representation of the phenomena mainly occurring in the system. The case represented here is Hmf (longer plate), but the phenomena are similar for Hme cases; and (b) Flow visualization with fluorescein for the case Hme A45P36, where "e" represents the end of the stratification plate and of the heat exchange zone

vary around $0.8 \mathrm{~cm} / \mathrm{s}$ for Hmf cases, and around $1.3 \mathrm{~cm} / \mathrm{s}$ for Hme cases. Concerning the average upward velocity, it was measured usually for profiles taken at $y=1.1 \mathrm{~m}$. If the results were not good at that line due to for instance unexpected phenomenon (bubbles flowing up thus creating a significant perturbation in the flow), the average upward velocity was measured at $y=1 \mathrm{~m}$. The values obtained vary around $0.33 \mathrm{~cm} / \mathrm{s}$ for Hmf cases and around $0.5 \mathrm{~cm} / \mathrm{s}$ for Hme 
cases. In this region, it can be noted that the values of velocities, maximum and average, tend to decrease with time. This phenomenon can be explained by the fact that the system temperature increases with time, thus reducing the density difference between the fluid near the heat exchange zone and the rest of the fluid in the system, which reduces the buoyancy force.

Zone B represents the reverse flow. This phenomenon occurs for both Hme and Hmf cases. Its magnitude cannot be observed clearly using PIV due to the fact that there is no visibility inside of the channel. Actually, the position of the devices do not allow to see the phenomena occurring in this part and the channel thickness is small compared to other scales in the system. However, if a line is placed at a small offset after the channel outlet, it is possible to see the downward flow that is partly going to re-enter the channel. The average velocity magnitudes $\bar{V}=\left(U^{2}+V^{2}\right)^{1 / 2}$ at those lines vary for Hme cases around 0.73 and $0.8 \mathrm{~mm} / \mathrm{s}$ for 1 and 3 hours respectively, and for Hmf cases around 0.56 and $0.74 \mathrm{~mm} / \mathrm{s}$ for 1 and 3 hours respectively.

It is possible to note that the velocities in these two zones are higher for Hme cases, which are the ones that have a better thermal stratification. It can be explained by the fact that the "loop" in this part (above the channel outlet) is more active and hence more efficient in heating this area. This is the reason why temperatures are higher at the top of the system for these cases compared with Hmf cases.

A visualization of the flow was done using fluorescein as a fluid tracker for the Hme case inclined at $45^{\circ}$ and heated with a flux of $3600 \mathrm{~W} / \mathrm{m}^{2}$. Fig. 9(b) shows the phenomena occurring in the two previously described zones.

Fig. 10 highlights the fact that by varying the inclination angle of the system, the angle at which the fluid re-enters the channel is also changing to keep close to an horizontal line. The fluid previously heated in the channel mostly stays in the upper part instead of going downard.

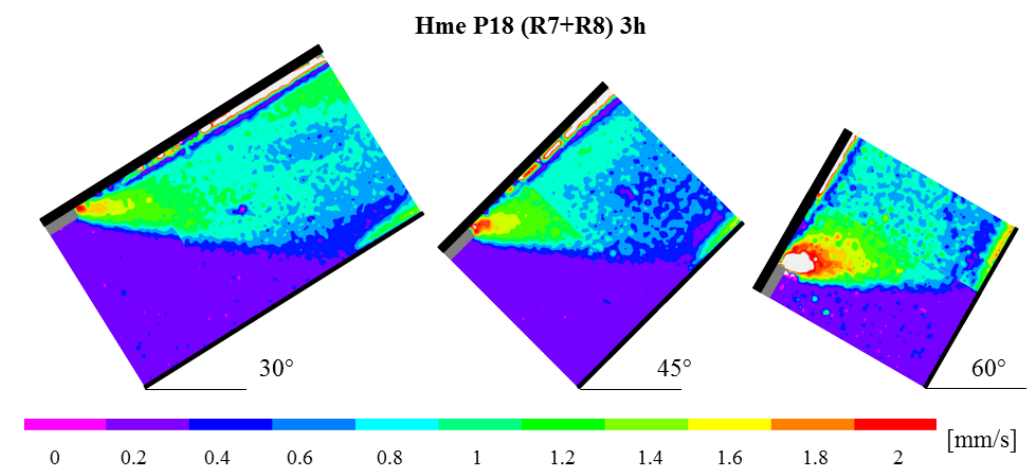

Figure 10: Comparison of the reverse flow for several angles after three hours for the shorter plate configuration (Hme) and a heat flux of $1800 \mathrm{~W} / \mathrm{m}^{2}$

Zone $\mathrm{C}$ is where the fluid is descending to the lower part of the system. For 
all cases, higher velocities have been observed close to the stratification plate, which can be explained by the fact that the fluid is taking the shortest way to loop inside the closed system. The average downward velocities in this region are taken along the profiles located in the middle of the acquisition regions $\mathrm{R} 2$, R3 and R5 (see Fig. 7). For both cases, a dramatic decrease in the velocities in this region can be observed. The values obtained for Hme cases are around $0.7 \mathrm{~mm} / \mathrm{s}$ at $1 \mathrm{~h}$ and decrease to $0.13 \mathrm{~mm} / \mathrm{s}$ at $t=3 \mathrm{~h}$. As for Hmf cases, the values vary around $1.2 \mathrm{~mm} / \mathrm{s}$ and $0.2 \mathrm{~mm} / \mathrm{s}$ for 1 and 3 hours respectively.

By looking at the values of velocities previously given, it is possible to understand that with time, the reverse flow is getting more and more important : taking into account the fact that the velocities of the plume (zone A) are decreasing with time while the reverse flow tends to increase with time, it makes it relatively even more important. It has the effect of reducing the global loop of the fluid in the system (after going up to the top, the fluid is going to the bottom of the system to be piped in the channel in this part), explaining the decrease of the downward velocities in zone $\mathrm{C}$. This effect is even more important for Hme cases.

Zone $\mathrm{D}$ is that of the aspiration of the fluid in the channel and the edge effects at the opposite corner. Part of the fluid in this last part goes upward along the bottom wall until a height which varies depending on the case. The phenomenon is accentuated when the ambient temperature is higher than the system temperature, resulting in the heating of the lower part of the system due to heat conduction in the glass, thus creating an ascending flow.

Fig. 11 shows an example of the velocity profile plots at different lines in the system for an average case: shorter plate (Hme) with an angle of inclination of $45^{\circ}$ and a heat flux of $2700 \mathrm{~W} / \mathrm{m}^{2}$ after three hours of charge.

It is possible to notice that the plume gets larger as it goes up, due to plume entrainment. Also, higher downward velocities are seen near the plate for both $\mathrm{R} 2$ and $\mathrm{R} 5$ zones. However, the upward motion is only observable in the bottom region (R2).

\section{Conclusion}

The system experimentally studied in this paper is a high aspect ratio cavity $(H / L=13)$ filled with water representing the storage part of an ICSSWH with indirect heat exchange with both the solar collector and the DHW. Only the charging part of the system is studied, and it lasts three hours for each experiment. Considering the inertia of the system, the flow is always transitional along the experiment (steady state cannot be reached). To model heat exchange with the solar collector, a constant heat flux is imposed, and the exchange zone is placed in the middle of the top wall. Three values of heat flux are studied $\left(1800,2700\right.$ and $\left.3600 \mathrm{~W} / \mathrm{m}^{2}\right)$, and the system is inclined with three angles relative to the horizontal $\left(30,45\right.$ and $\left.60^{\circ}\right)$.

Compared with a previously studied case heated at the bottom, the temperature stratification inside the system is enhanced : while the maximum temperature difference measured in the previous system was of $4.2{ }^{\circ} \mathrm{C}$ after three 


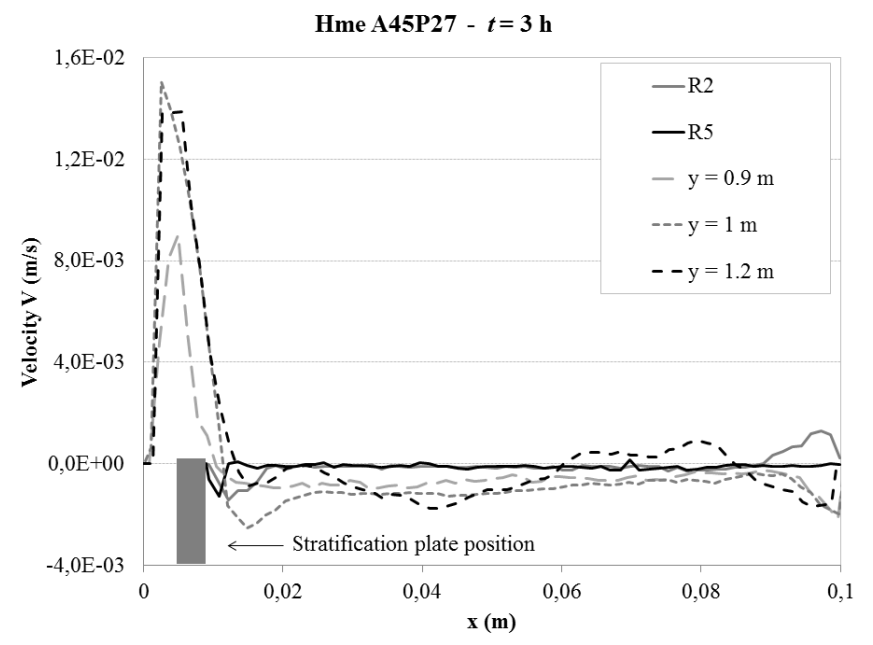

Figure 11: Velocity profiles for the shorter plate case (Hme) with an inclination angle of 45 ${ }^{\circ}$ and a heat flux of $2700 \mathrm{~W} / \mathrm{m}^{2}$ at $t=3 \mathrm{~h}$

hours for a case heated with a constant heat flux of $5400 \mathrm{~W} / \mathrm{m}^{2}$ and inclined with $30^{\circ}$, it now reaches $20.1^{\circ} \mathrm{C}$ for the same duration and with a greater angle of inclination $\left(45^{\circ}\right)$ and a smaller flux injected $\left(3600 \mathrm{~W} / \mathrm{m}^{2}\right)$.

Changing the position of the heat exchange zone had the effet to reduce the buoyancy forces inside the system, and by placing the heating zone near the channel outlet, a reverse flow clearly appeared. Though both these phenomena are responsible for a better stratification, the reverse flow is the one having more influence. It also increases with time, reducing the global loop of fluid inside the system. The main risk is that after a long period of charge, the fluid no longer moves at the bottom part, resulting in a dead volume under the heating zone.

CFD studies of this system, as well as global model for the determination of the annual performances should allow to further understand the phenomena and see if a better thermal stratification actually increases global system efficiency.

\section{References}

[1] Z. Lavan, J. Thompson, Experimental study of thermally stratified hot water storage tanks, Solar Energy 19 (1977) 519-524.

URL http://www.sciencedirect.com/science/article/pii/0038092X77901086

[2] B. Chaouachi, O. Helal, S. Gabsi, C. Bouden, Energetic Performances Study of an Integrated Collector Storage Solar Water Heater, American Journal of Engineering and Applied ... 3 (1) (2010) 152-158.

URL http://scholar.google.com/scholar?hl=en\&btnG=Search\&q=intitle:Energetic+Performance 
[3] ATC Solar, SlimSolar.

[4] A. Mohamad, Integrated solar collectorstorage tank system with thermal diode, Solar Energy 61 (3) (1997) 211-218. doi:10.1016/S0038092X(97)00046-7.

URL http://linkinghub.elsevier.com/retrieve/pii/S0038092X97000467

[5] Soletrol, Popsol, Topsol.

URL http://www.soletrol.com.br/

[6] M. Y. Haller, C. A. Cruickshank, W. Streicher, S. J. Harrison, E. Andersen, S. Furbo, Methods to determine stratification efficiency of thermal energy storage processes â Review and theoretical comparison, Solar Energy 83 (10) (2009) 1847-1860. doi:http://dx.doi.org/10.1016/j.solener.2009.06.019.

URL http://www.sciencedirect.com/science/article/pii/S0038092X09001546

[7] A. Castell, M. Medrano, C. SolÃ, L. F. Cabeza, Dimensionless numbers used to characterize stratification in water tanks for discharging at low flow rates, Renewable Energy 35 (10) (2010) 2192-2199. doi:http://dx.doi.org/10.1016/j.renene.2010.03.020.

URL http://www.sciencedirect.com/science/article/pii/S0960148110001370

[8] L.-y. Wu, R. B. Bannerot, An experimental investigation of the effect of water removal and replacement on the thermal stratification in a horizontal water storage tank, Tech. Rep. November (1984).

[9] H. Garg, U. Rani, Theoretical and experimental studies on collector/storage type solar water heater, Solar Energy 29 (6).

URL http://www.sciencedirect.com/science/article/pii/0038092X8290055X

[10] S. Kaushik, R. Kumar, H. Garg, Effect of baffle plate on the performance of a triangular built-in-storage solar water heater, Energy conversion and management.

URL http://www.sciencedirect.com/science/article/pii/019689049598898W

[11] D. Faiman, H. Hazan, I. Laufer, Reducing the heat loss at night from solar water heaters of the integrated collectorstorage variety, Solar Energy 71 (2) (2001) 87-93. doi:10.1016/S0038-092X(01)00021-4.

URL http://linkinghub.elsevier.com/retrieve/pii/S0038092X01000214

[12] M. Smyth, P. Eames, B. Norton, A comparative performance rating for an integrated solar collector/storage vessel with inner sleeves to increase heat retention, Solar Energy 66 (4) (1999) 291-303. doi:10.1016/S0038092X(99)00027-4.

URL http://linkinghub.elsevier.com/retrieve/pii/S0038092X99000274

[13] M. Smyth, P. Eames, B. Norton, Annual performance of heat retaining integrated collector/storage solar water heaters in a northern maritime 
climate, Solar Energy 70 (5) (2001) 391-401. doi:10.1016/S0038-

092X(00)00161-4.

URL http://linkinghub.elsevier.com/retrieve/pii/S0038092X00001614

[14] M. Smyth, P. Eames, B. Norton, Heat retaining integrated collector/storage solar water heaters, Solar energy 75 (2003) 27-34.

URL http://www.sciencedirect.com/science/article/pii/S0038092X03002299

[15] J. V. Souza, G. Fraisse, M. Pailha, S. Xin, Experimental study of a partially heated cavity of an integrated collector storage solar water heater (ICSSWH), Solar Energy 101 (2014) 53-62. doi:10.1016/j.solener.2013.11.023. URL http://linkinghub.elsevier.com/retrieve/pii/S0038092X13005045

[16] E. Hahne, Y. Chen, Numerical study of flow and heat transfer characteristics in hot water stores, Solar Energy 64 (98) (1998) 9-18.

URL http://www.sciencedirect.com/science/article/pii/S0038092X98000516

[17] J. Nelson, A. Balakrishnan, S. Srinivasa Murthy, Experiments on stratified chilled water tanks, Journal of Refrigeration submitted 22 (September 1997) (1999) 216-234.

URL http://scholar.google.com/scholar?hl=en\&btnG=Search\&q=intitle: Experiments+on+strati

[18] J. Souza, Conception et optimisation dun capteur solaire thermique innovant adapté à la rénovation énergétique grâce à lintégration du stockage, Ph.D. thesis, Le Bourget du Lac (2012).

[19] G. Fraisse, M. Pailha, M. Swiatek, C. Paulus, J. Souza, M. Cosnier, Study of a new Integrated Solar Collector, in: ISES Solar World Congress, Vol. 00, 2013.

[20] G. Fraisse, Compte-rendu de fin de projet ANR Reneausol, Tech. rep. (2009).

[21] A. Barzegar, A. A. Dehghan, Transient Thermal Behavior of a Vertical Solar Storage Tank with a Mantle Heat Exchanger during No-Flow Operation, Journal of Applied Fluid Mechanics 2 (1) (2009) 55-69.

[22] F. Dupont, F. Ternat, S. Samot, R. Blonbou, Two-dimension experimental study of the reverse flow in a free convection channel with active walls differentially heated, Experimental Thermal and Fluid Science 47 (2013) 150-157. doi:10.1016/j.expthermflusci.2013.01.010. URL http://linkinghub.elsevier.com/retrieve/pii/S0894177713000289

[23] E. Sparrow, G. Chrysler, L. Azevedo, Observed flow reversals and measured-predicted Nusselt numbers for natural convection in a one-sided heated vertical channel, Journal of heat transfer.

URL http://cat.inist.fr/?aModele=afficheN\&cpsidt $=9679572$ 
[24] R. Li, M. Bousetta, E. Chénier, G. Lauriat, Effect of surface radiation on natural convective flows and onset of flow reversal in asymmetrically heated vertical channels, International Journal of Thermal ...65 (2013) $9-27$.

URL http://www.sciencedirect.com/science/article/pii/S1290072912002979

[25] B. Brangeon, Contribution à l'étude numérique de la ventilation naturelle dans des cavités ouvertes par la simulation des grandes échelles. Application au rafraîchissement passif, Ph.D. thesis, Université de La Réunion (2012). URL http://hal .archives-ouvertes .fr/tel-00763390/

[26] S. Samot, F. Dupont, F. Penot, Mesure de température dans un écoulement renversé à la sortie d'un thermosiphon vertical chauffé à flux constant., SFT 2010 France.

URL http://gsite.univ-provence.fr/gsite/Local/sft/dir/user-3775/documents/actes/Congres

[27] R. Khanal, C. Lei, Flow reversal effects on buoyancy induced air flow in a solar chimney, Solar Energy 86 (9) (2012) 2783-2794. doi:10.1016/j.solener.2012.06.015.

URL http://linkinghub.elsevier.com/retrieve/pii/S0038092X12002277

[28] A. Bejan, Convection heat transfer (2004) 695.

URL http://www.lavoisier.fr/livre/notice.asp?id=0KLWR3ALRA00WB 